\title{
Avaliação Operacional do Controle mecânico de Plantas AQUÁTICAS IMERSAS NO RESERVATÓRIO DE JUPIÁ ${ }^{1}$
}

\author{
Operational Evaluation of Mechanical Control of Aquatic Macrophytes Submerged in the \\ Jupia Reservoir
}

\author{
VELINI, E.D. ${ }^{2}$, CORREA, M.R. ${ }^{3}$, TANAKA, R.H. ${ }^{4}$, BRAVIN, L.F. ${ }^{5}$, ANTUNIASSI, U.R. ${ }^{6}$, \\ CARVALHO, F.T. ${ }^{7}$ e GALO, M.L.B.T. ${ }^{8}$
}

\begin{abstract}
RESUMO - O presente trabalho foi realizado com o objetivo de estudar a coleta e o descarte de plantas aquáticas em diferentes locais e infestações do sistema Tietê/Paraná, no reservatório de Jupiá. A operação foi realizada com auxílio de instrumentação instalada em uma colhedora de plantas aquáticas, com sistema de GPS dotado de sinal de correção diferencial. Os tempos gastos para carregar e descarregar a colhedora foram determinados por cronometragem, e a distância do ponto final de coleta ao ponto de descarte e o tempo de deslocamento, por cronometragem e uso de GPS convencional. Em algumas coletas foram demarcados polígonos, instruindo-se o operador a trabalhar exclusivamente na área correspondente. A interpretação dos resultados permitiu determinar a participação do tempo de coleta em relação ao tempo total de operação, indicando um valor significativo do ponto de vista operacional $(>70 \%)$. Considerando o descarte em áreas infestadas com "taboa", o deslocamento total médio foi de apenas $383 \mathrm{~m}$, com gasto médio de 200,96 s. Os valores de capacidade operacional da colhedora oscilaram entre 0,23 e 1,60 ha $\mathrm{h}^{-1}$, indicando valor

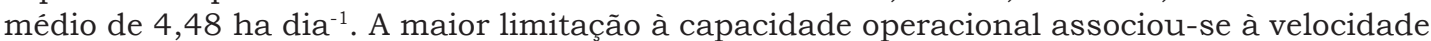
média de deslocamento, com maior agravante em áreas com altas infestações ou profundas. Considerando-se o deslocamento da colhedora, houve grande dificuldade de orientação em condições normais de operação, inviabilizando a manutenção de espaçamentos uniformes entre as faixas de coleta e sobrepondo as passagens. Conclui-se que a avaliação operacional indicou a impossibilidade de operar a colhedora sem o auxílio de um sistema de navegação que permita orientar a sua movimentação nas áreas de controle.
\end{abstract}

Palavras-chave: controle mecânico, GPS, Egeria densa, Ceratophyllum demersum.

\begin{abstract}
This work aimed to study the harvest and discard of aquatic plants from different places and infestation in the Tiete/Parana River system. The operation was performed with equipment installed at an aquatic plant harvester, using GPS system with differential correction signal. The time spent to load and unload the harvester was determined by timing with a stop watch, and the distance between the collection final point to the discard point as well the displacement time were determined by timing and GPS. In some collections, polygons were marked to instruct the machine operator to work exclusively in the corresponding area. Data interpretation permitted to determine the collect time participation in relation to the operation total time, indicating a significant value from an operational point of view (>70). Considering discard in areas infested with cattail, the mean total displacement was only $383 \mathrm{~m}$, with 200.96s of mean time spent. Values of the harvester operational capacity oscillated between 0.23 and $1.60 \mathrm{ha} \mathrm{h}^{-1}$, indicating a mean value of $4.48 \mathrm{ha} \mathrm{h} \mathrm{h}^{-1}$ per day. The main limitation to the operational capacity was associated with the mean displacement
\end{abstract}

1 Recebido para publicação em 5.1.2005 e na forma revisada em 6.4.2005.

2 Prof. Dr., Departamento de Produção Vegetal/Agricultura, FCA/UNESP, Caixa Postal 237, 18610-970 Botucatu-SP, $<$ velini@fca.unesp.br>; ${ }^{3}$ Eng. Agr., M.S., Programa de Pós-Graduação em Agricultura, Departamento de Produção Vegetal/Agricultura, FCA/UNESP, Botucatu-SP. ${ }^{4}$ Eng.-Agr., M.S., CESP/São Paulo. ${ }^{5}$ Eng. Naval, M.S., Professor da Faculdade de Tecnologia de Botucatu - FATEC, Botucatu-SP. ${ }^{6}$ Prof. Dr., Departamento de Engenharia Rural, FCA/UNESP, Botucatu-SP. ${ }^{7}$ Prof. Dr., Dep. de Biologia e Zootecnia, FEIS/UNESP, Av. Brasil, n 56, Centro, 15385-000 Ilha Solteira-SP, <ftadeu@bio.feis.unesp.br>.

Planta Daninha, Viçosa-MG, v. 23, n. 2, p. 277-285, 2005 
velocity, intensifying in deeper and more infested areas. As for harvester displacement, there was great difficulty in orientation under normal operational conditions, making it impractical to maintain uniform spacing between the collect tracks. It was concluded that the operational evaluation indicated the unfeasibility of operating the machine without a GPS system allowing to guide the harvester throughout the control areas.

Key words: mechanical control, GPS, Egeria densa, Ceratophyllum demersum.

\section{INTRODUÇÃO}

As macrófitas aquáticas submersas, flutuantes ou emersas, vêm causando sérios prejuízos à geração de energia em usinas hidrelétricas, tanto pela infestação quanto pela interrupção temporária da geração de energia elétrica (Pompêo \& Moschini-Carlos, 2003). Velini (2000) e Braga (2002) afirmam que o carregamento de parte dos fertilizantes utilizados em culturas agrícolas, além da grande carga de esgotos residenciais e industriais, tem levado cursos e reservatórios de água, naturais ou artificiais, a uma condição de desequilíbrio, caracterizada pela grande disponibilidade de nutrientes, acelerando o crescimento da vegetação aquática indesejável.

O reservatório de Jupiá, localizado na divisa dos Estados de São Paulo e Mato Grosso do Sul, foi gerado pela construção da Usina Hidrelétrica Souza Dias. Possui área de inundação de $330 \mathrm{~km}^{2}$ e recebe águas dos rios Paraná, Tietê e Sucuriu, além de vários outros rios de menor porte (Figura 1). As águas dos rios Tietê e Paraná são represadas, acima de Jupiá, pelas barragens da Usina Hidrelétrica de Ilha Solteira e da Usina Hidrelétrica de Três Irmãos.

O reservatório da UHE Souza Dias (Jupiá) apresenta importantes problemas com infestação de plantas aquáticas imersas, como Egeria densa, Egeria najas e Ceratophyllum demersum, sobretudo em locais com menor profundidade ao longo do leito represado do rio Tietê e em áreas do rio Paraná com maior transparência da água. Em períodos de grande vazão nos rios Paraná ou Tietê, essas espécies podem ser deslocadas e obstruir as tomadas de água das unidades geradoras, promovendo queda ou interrupção na produção de energia elétrica e tornando necessária a operação de limpeza das grades de proteção e a substituição de possiveis painéis de grade danificados.
Estudos realizados, destacando-se Marcondes et al. (2002, 2003), indicaram que o alto fluxo de água ao longo dos rios Tietê e Paraná corresponde à maior restrição ao uso do controle químico de plantas imersas, sobretudo quando são utilizados herbicidas que demandam longo período de contato para que possam efetivamente controlar as plantas. Uma alternativa foi o desenvolvimento de técnicas e equipamentos necessários ao uso do controle mecânico de plantas aquáticas submersas.

O controle mecânico utilizando embarcações equipadas com sistema de recolhimento de plantas é freqüentemente observado no exterior, porém pouco empregado no Brasil. Essa opção de controle, segundo Velini (2000), é de grande potencial em programas de manejo integrado de plantas aquáticas, podendo ser utilizada em pontos com início de infestação de plantas marginais, imersas ou emersas; além disso, pode ser usado na limpeza emergencial de pontos de tomada de água de bombas e turbinas, como um sistema auxiliar, reduzindo o acúmulo de plantas nas grades de proteção.

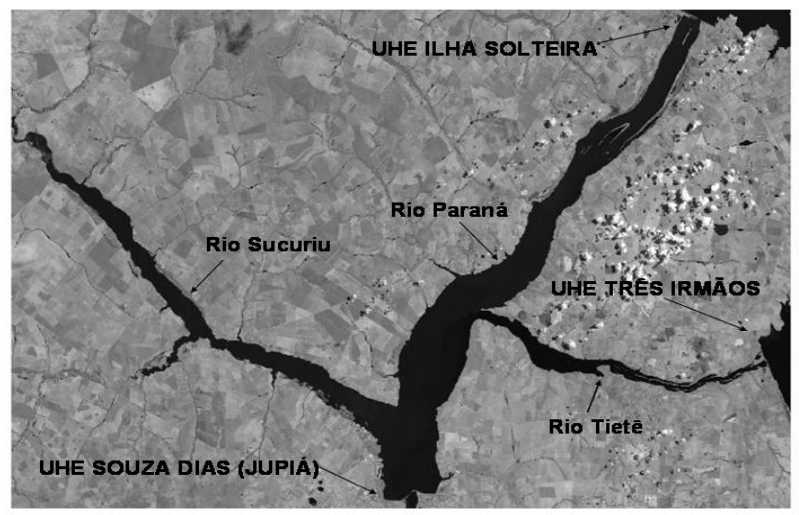

Figura 1 - Imagem da UHE Souza Dias (Jupiá), seu reservatório e rios formadores. 
Com base nesse contexto, foi realizado um ensaio de avaliação operacional de controle mecânico de plantas aquáticas imersas no reservatório de Jupiá, utilizando uma embarcação apropriada, com a finalidade de desenvolver procedimentos técnicos e/ou legais para viabilizar o uso desse tipo de equipamento no país.

\section{MATERIAL E MÉTODOS}

A fase inicial do estudo foi realizada, por iniciativa conjunta da CESP e UNESP, pela aquisição de uma colhedora de plantas aquáticas do modelo H10-800 (Figura 2A) e de uma esteira de margem SC-80 (Figura 2B), fabricadas pela empresa canadense AQUAMARINE.

Deve ser ressaltado que esta colhedora, por ser a única em operação e pela sua limitada capacidade de trabalho, não representa, isoladamente, a solução para os problemas com plantas aquáticas encontradas no presente reservatório. A função mais importante dessa primeira unidade foi a de proporcionar aos técnicos, aos pesquisadores envolvidos no projeto e aos órgãos fiscalizadores a oportunidade de desenvolver procedimentos técnicos e/ou legais para viabilizar e normatizar o uso desse tipo de equipamento no Brasil.

A maior limitação ao uso do controle mecânico em larga escala no reservatório refere-se à destinação das plantas coletadas. Uma alternativa encontrada foi a deposição das plantas sobre áreas do próprio reservatório infestadas por plantas aquáticas marginais (Figura 3). Uma análise inicial indicou que o procedimento mostrou-se viável do ponto de vista operacional; para suportar a sua implementação e utilização em uma escala mínima, a fim de que seus efeitos ambientais pudessem ser avaliados, com as devidas autorizações dos órgãos ambientais e de saúde pública competentes, tornou-se necessário localizar áreas infestadas com plantas marginais em que a expansão das infestações havia ocorrido internamente ao perímetro de inundação do reservatório.

O estudo operacional foi realizado após a instrumentação da colhedora com um sistema de GPS (Figura 4) com sinal de correção e acurácia de $0,4 \mathrm{~m}$, avaliada durante a operação. $O$ GPS adquiriu informações a cada intervalo de $1 \mathrm{~m}$ ou $1 \mathrm{~s}$ (atendendo à condição que ocorresse primeiro). A interpretação dos resultados permitiu determinar com que precisão (em termos de posicionamento) a colhedora se deslocou, a velocidade instantânea a cada segundo (ou metro) e o deslocamento total para que o reservatório da colhedora fosse completamente preenchido.

Os tempos necessários para carregar e descarregar o reservatório foram determinados

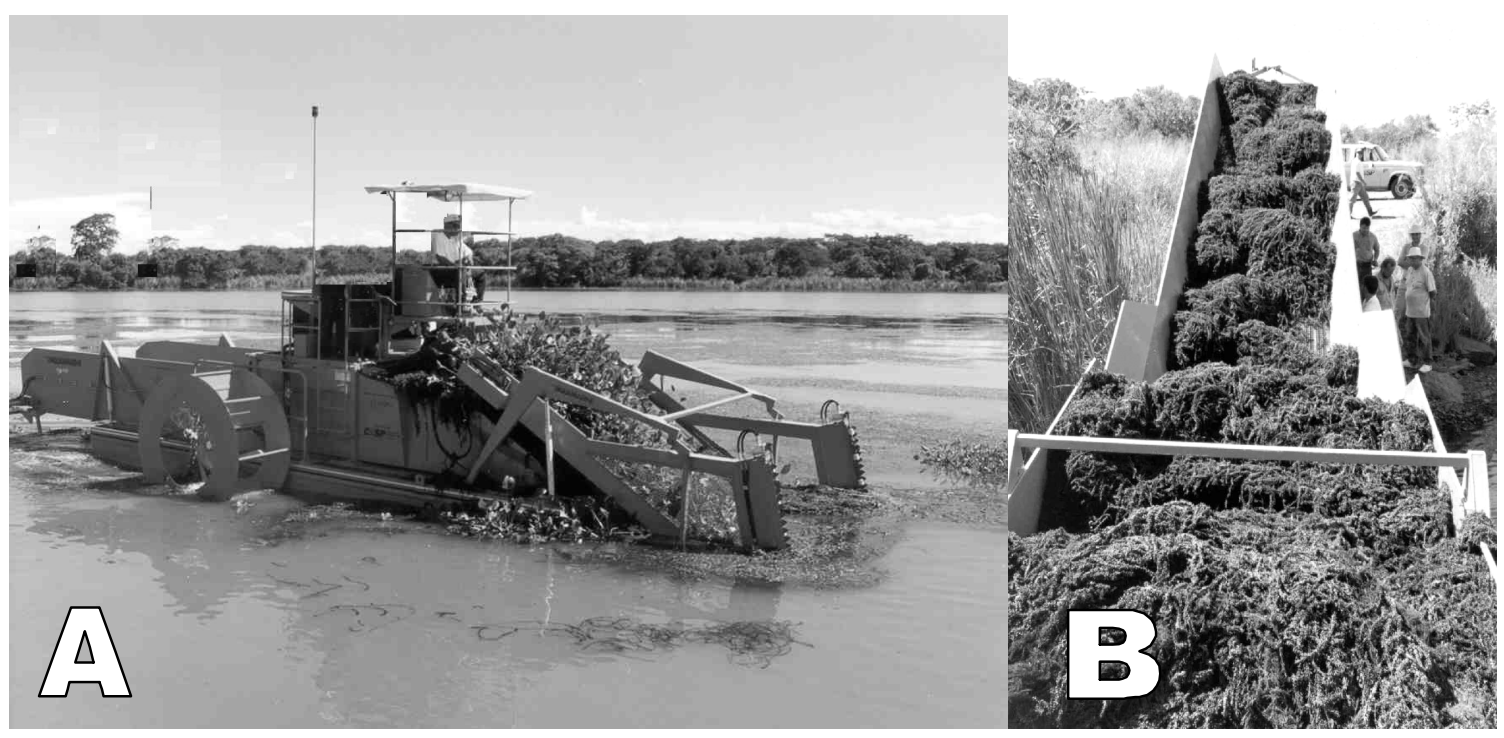

Figura 2 - Colhedora de plantas aquáticas (A) e esteira de margem (B) em operação no reservatório de Jupiá. 


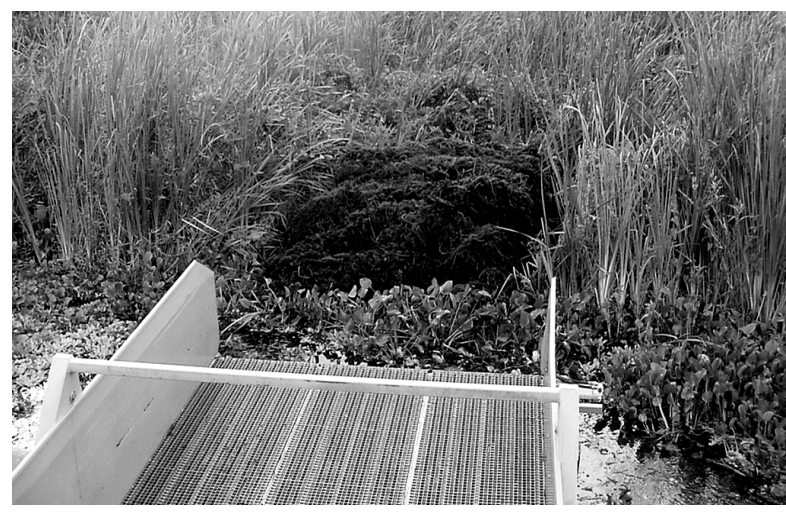

Figura 3 - Disposição das plantas aquáticas submersas coletadas sobre infestações de plantas marginais.

por cronometragem. A distância do ponto final de coleta ao ponto de descarte, além do tempo de deslocamento, foram determinados por cronometragem e através do uso de GPS convencional (sem sinal de correção e acurácia de $5 \mathrm{~m}$ ). Foram realizadas coletas nos seguintes locais e condições:

a) Três coletas no canal principal do rio Tietê, na altura do município de Itapura; em uma delas procurou-se demarcar um poligono, circunscrevendo as passadas da colhedora que deveriam ser paralelas.

b) Quatro coletas na lagoa Vírgula, no rio Tietê, sendo duas em áreas infestadas com Egeria najas e Egeria densa e outras duas em áreas infestadas quase que exclusivamente com C. demersum. Nessas quatro áreas, a coleta foi feita segundo o procedimento convencional; o GPS foi utilizado para registro das condições operacionais, mas não para a orientação do operador.

c) Três coletas na lagoa Marginal, localizada imediatamente abaixo da ponte de Itapura, na margem esquerda do rio Tietê. Duas coletas foram realizadas após a demarcação de polígonos circunscreventes às passadas da colhedora que deveriam ser paralelas (evitando a sobreposição com redução da capacidade operacional). Em uma terceira oportunidade a coleta foi feita ao longo de linhas retas de margem a margem, para que a estimativa da biomassa no sistema tivesse a máxima representatividade. Nesse caso, o objetivo foi determinar a melhor condição

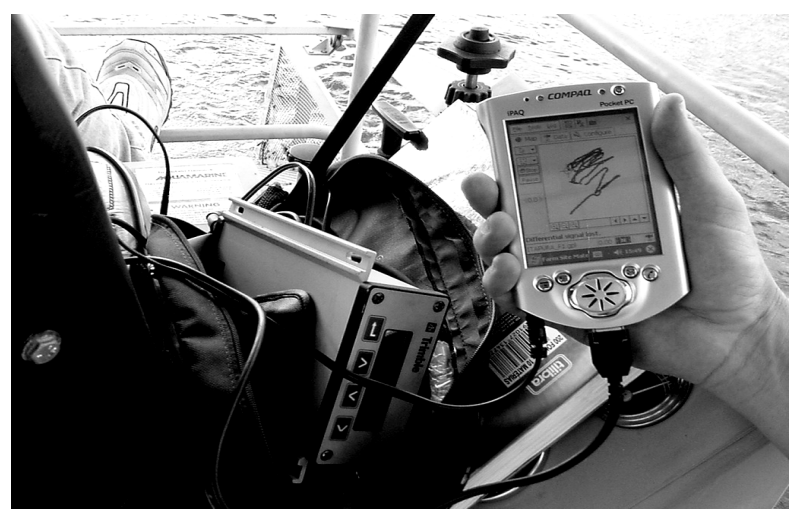

Figura 4 - Sistema de GPS utilizado na avaliação operacional da colhedora de plantas aquáticas.

operacional para que a colhedora pudesse ser usada na estimativa da quantidade total de biomassa presente no sistema Tietê/Paraná.

d) Outras cinco coletas foram conduzidas nas lagoas Ferradura e Pernilongo, no rio Paraná, simulando operações convencionais (sem auxílio do GPS), com demarcação de polígonos circunscreventes e coletas ao longo de retas de margem a margem (estimativa da biomassa).

Embora o volume total do reservatório da colhedora fosse de $22,7 \mathrm{~m}^{3}$, para aumentar a exatidão das avaliações, determinou-se a espessura média da camada de plantas depositada no compartimento de carga da colhedora. Foi possivel determinar que o volume médio transportado, nas condições deste estudo, foi de $19,98 \pm 0,73 \mathrm{~m}^{3}$ (intervalo de confiança a $5 \%$ de probabilidade), adotando-se $20 \mathrm{~m}^{3}$ como valor médio. A determinação do peso de plantas por $\mathrm{m}^{3}$ coletado foi feito determinando-se o peso de plantas acomodado em um recipiente com este volume, observando-se pesos de $149,86 \pm 11,9 \mathrm{~kg}$ (intervalo de confiança a $5 \%$ de probabilidade). Utilizou-se o valor médio de $150 \mathrm{~kg} \mathrm{~m}^{-3}$.

As espécies Egeria densa, Egeria najas e Cerathophyllum demersum apresentaram, respectivamente, teores médios de água de 90,60, 90,85 e 89,14\%, com média geral de $90,20 \%$ para as três espécies, conforme conjunto de informações apresentado por Corrêa (2002) e Corrêa et al. (2002, 2003). Considerando todas as avaliações, os teores 
de água para as três espécies foram bastante próximos aos informados pelos autores, e a média geral foi de $90,76 \%$, equivalendo a $9,24 \%$ de matéria seca.

\section{RESULTADOS E DISCUSSÃO}

Os principais resultados da avaliação operacional da colhedora de plantas aquáticas AQUAMARINE, operando nas condições do reservatório de Jupiá, são apresentados nas Tabelas 1 e 2 .

A primeira observação importante referese à elevada participação do tempo de coleta em relação ao tempo total, incluindo o deslocamento até o ponto de descarte, o retorno à área de controle e a operação de descarregamento. $\mathrm{O}$ valor médio expresso em porcentagem da soma total de tempos equivale ao rendimento operacional e foi de $70,10 \%$, ou seja, mais de $70 \%$ do tempo foi consumido coletando plantas. Esse valor médio é bastante alto e indica que, do ponto de vista operacional, a alternativa de descarte selecionada, sobre infestações de plantas marginais, é bastante adequada. O deslocamento total médio (nos dois sentidos) para a realização dessa operação foi de apenas $383 \mathrm{~m}$, consumindo, em média, 201,0 s. Embora haja variações, o tempo médio do descarregamento foi de apenas 148,2 s.

Uma observação inicial dos dados indicou a abundância de biomassa fresca como principal determinante do rendimento operacional. Para melhor analisar a dependência entre as variáveis, foram feitas análises de regressão segundo o modelo $y=10^{(a+b x)}$, em que " $y$ " representa o rendimento operacional e " $\mathrm{x}$ " a abundância de biomassa expressa em $\mathrm{m}^{3} \mathrm{de}$ material fresco ha ${ }^{-1}$. Considerando que quando não há biomassa no local o rendimento operacional é de $100 \%$, pois não há necessidade da operação de descarregamento de plantas, estabeleceu-se como sendo "2" o valor da constante "a". Os dados originais e os ajustados são representados na Figura 5.

A análise das informações indica que, embora o valor médio do rendimento operacional tenha sido elevado, esta característica pode ser bastante reduzida em áreas com grande abundância de biomassa de plantas aquáticas imersas. Para uma abundância de biomassa de $400 \mathrm{~m}^{3}$ de material fresco ha-1 o rendimento operacional previsto pelo modelo é de $39,26 \%$. Nessa condição, mais de $60 \%$ do tempo de trabalho seria consumido em deslocamentos até o ponto de descarregamento e nessa operação. Embora os tempos de descarregamento tenham variado entre 111 e $210 \mathrm{~s}$, a análise da operação, no local, indica que não há como reduzi-los. Os menores valores foram encontrados em locais em que as plantas marginais afundaram sob o peso das plantas imersas, sendo possivel descarregar todo o volume de $20 \mathrm{~m}^{3}$ em um único ponto. Os maiores tempos foram obtidos quando as plantas marginais não afundaram; foi necessário movimentar a colhedora e buscar um segundo local quando o monte de plantas imersas alcançou a altura da rampa de descarga da colhedora.

Os valores estimados para a capacidade operacional oscilaram entre 0,23 e 1,60 ha h-1. $\mathrm{O}$ valor médio foi de $0,56 \mathrm{ha}^{-1}$, ou o equivalente a 4,48 ha dia $^{-1}$, com um total de oito horas diárias de trabalho. Como conseqüência da alteração da velocidade média durante a operação de coleta e do rendimento operacional, os valores mostraram-se bastante dependentes da abundância da biomassa de plantas imersas, expressa em $\mathrm{m}^{3}$ de material fresco ha ${ }^{-1}$. Para melhor representar essa relação, foram feitas análises de regressão segundo o modelo:

$$
y=\frac{1}{a\left(1-10^{-c(x+b)}\right)}
$$

em que "y" representa a capacidade operacional, em "ha $\mathrm{h}^{-1}$ "; " $\mathrm{x}$ " representa a quantidade de biomassa expressa em " $\mathrm{m}^{3}$ de material fresco ha-1"; e "a", "b" e "c" são constantes do modelo utilizado. Os principais resultados da análise de regressão são apresentados na Tabela 2 e indicaram que o modelo ajustado representa $82,27 \%$ de toda a variação observada nos resultados referentes à capacidade operacional (Figura 6).

A análise do gráfico e dos valores das constantes do modelo indica que, com o aumento da abundância de biomassa, a capacidade operacional decresce de modo não-linear e tende à assintota " 0,2732 ha $^{-1}{ }^{-1}$. Esta é a capacidade operacional esperada mesmo em locais com quantidades de biomassa por unidade de área superiores às observadas no estudo.

Planta Daninha, Viçosa-MG, v. 23, n. 2, p. 277-285, 2005 
Tabela 1 - Resultados das determinações de tempos e deslocamentos para cada carga de $20 \mathrm{~m}^{3}$ da colhedora; atividades de coleta, deslocamento e descarga; e porcentagens do tempo consumidas em cada atividade

\begin{tabular}{|c|c|c|c|c|c|c|c|c|c|c|c|c|}
\hline \multirow{2}{*}{ Local de Coleta } & \multirow{2}{*}{$\begin{array}{l}\text { Condi- } \\
\text { ção }\end{array}$} & \multicolumn{5}{|c|}{ Coleta } & \multicolumn{3}{|c|}{ Deslocamento (ida e volta) } & \multicolumn{3}{|c|}{ Descarregamento } \\
\hline & & (s) & $(\%)$ & $(\mathrm{m})$ & $\left(\mathrm{m} \mathrm{s}^{-1}\right)$ & $\left(\mathrm{m}^{2}\right)$ & (s) & $(\%)$ & $(\mathrm{m})$ & $\left(\mathrm{m} \mathrm{s}^{-1}\right)$ & (s) & $(\%)$ \\
\hline Itapura 1 & Canal & 2.048 & 89,96 & 902,4 & 0,39 & $2.407,05$ & 107,5 & 4,72 & 200 & 1,86 & 121,2 & 5,32 \\
\hline Itapura 2 & Canal & 1.167 & 75,72 & 715,4 & 0,61 & $2.146,26$ & 254,2 & 16,50 & 500 & 1,97 & 120,0 & 7,79 \\
\hline Itapura 3 & Canal & 856 & 65,46 & 445,7 & 0,52 & $1.337,10$ & 331,7 & 25,36 & 640 & 1,93 & 120,0 & 9,18 \\
\hline Média & Canal & 1.357 & 77,04 & 654,5 & 0,51 & $1.963,47$ & 231,1 & 15,53 & 447 & 1,92 & 120,4 & 7,43 \\
\hline Vírgula 1 & Lagoa & 462 & 43,68 & 224,4 & 0,49 & 673,05 & 458,6 & 43,36 & 840 & 1,83 & 137,0 & 12,95 \\
\hline Vírgula 2 & Lagoa & 299 & 40,45 & 162,9 & 0,54 & 488,73 & 313,1 & 42,36 & 600 & 1,92 & 127,0 & 17,18 \\
\hline Vírgula 3 & Lagoa & 555 & 59,62 & 340,5 & 0,61 & $1.021,50$ & 265,0 & 28,46 & 480 & 1,81 & 111,0 & 11,92 \\
\hline Vírgula 4 & Lagoa & 422 & 69,23 & 240,1 & 0,57 & 720,39 & 49,6 & 8,14 & 100 & 2,02 & 138,0 & 22,64 \\
\hline Média & \begin{tabular}{|l|} 
Lagoa \\
\end{tabular} & 434,5 & 53,24 & 242,0 & 0,55 & 725,92 & 271,6 & 30,58 & 505 & 1,89 & 128,3 & 16,17 \\
\hline Ponte de Itapura 1 & Lagoa & 1.560 & 84,70 & & & & 71,7 & 3,90 & 140 & 1,95 & 210,0 & 11,40 \\
\hline Ponte de Itapura 2 & Lagoa & 1.160 & 64,93 & 528,1 & 0,46 & $1.584,36$ & 476,5 & 26,67 & 940 & 1,97 & 150,0 & 8,40 \\
\hline Ponte de Itapura 3 & Lagoa & 1.200 & 84,45 & 594,4 & 0,50 & $1.783,08$ & 89,9 & 6,33 & 180 & 2,00 & 131,0 & 9,22 \\
\hline Média & Lagoa & $1.306,7$ & 78,03 & 561,2 & 0,48 & $1.683,72$ & 212,7 & 12,30 & 420 & 1,98 & 163,7 & 9,67 \\
\hline Pernilongo 1 & Lagoa & 612 & 74,29 & 882,5 & 1,44 & $2.647,59$ & 20,9 & 2,53 & 40 & 1,92 & 191,0 & 23,18 \\
\hline Pernilongo 2 & Lagoa & 659 & 73,91 & $1.319,8$ & 2,00 & $3.959,28$ & 112,7 & 12,64 & 220 & 1,95 & 120,0 & 13,46 \\
\hline Pernilongo 3 & Lagoa & 1.102 & 83,28 & $1.144,9$ & 1,04 & $3.434,61$ & 50,2 & 3,80 & 100 & 1,99 & 171,0 & 12,92 \\
\hline Média & Lagoa & 791 & 77,16 & $1.115,7$ & 1,49 & \begin{tabular}{|l|}
$3.347,16$ \\
\end{tabular} & 61,3 & 6,32 & 120 & 1,95 & 160,7 & 16,52 \\
\hline Ferradura 1 & Lagoa & 752 & 69,17 & 427,2 & 0,57 & $1.281,63$ & 154,1 & 14,18 & 280 & 1,82 & 181,0 & 16,65 \\
\hline Ferradura 2 & Lagoa & 1.205 & 72,69 & 732,5 & 0,61 & $2.197,41$ & 258,7 & 15,61 & 480 & 1,86 & 194,0 & 11,70 \\
\hline Média & Lagoa & 978,5 & 70,93 & 579,8 & 0,59 & $1.739,52$ & 206,4 & 14,89 & 380 & 1,84 & 187,5 & 14,18 \\
\hline Médi & & 937,27 & 70,10 & 611,5 & 0,74 & $1.834,43$ & 201,0 & 16,97 & 383 & 1,92 & 148,2 & 12,93 \\
\hline
\end{tabular}

Tabela 2 - Locais e condições em que foi realizada a avaliação operacional da colhedora de plantas aquáticas; e informações sobre acúmulos de biomassa de plantas aquáticas submersas e capacidade operacional

\begin{tabular}{|c|c|c|c|c|c|c|c|c|}
\hline \multirow{2}{*}{ Local de Coleta } & \multirow{2}{*}{ Condição } & \multirow{2}{*}{$\begin{array}{c}\mathrm{MF} \\
\left(\mathrm{m}^{3} \mathrm{ha}^{-1}\right)\end{array}$} & MF & MS & \multirow{2}{*}{ Carga $\mathrm{h}^{-1}$} & \multirow{2}{*}{$\underset{\left(\mathrm{m}^{3} \mathrm{~h}^{-1}\right)}{\mathrm{MF}}$} & \multirow{2}{*}{$\begin{array}{c}\text { MF } \\
\left(\mathrm{t} \mathrm{h}^{-1}\right)\end{array}$} & \multirow{2}{*}{ ha $h^{-1}$} \\
\hline & & & \multicolumn{2}{|c|}{$\left(\mathrm{t} \mathrm{ha}^{-1}\right)$} & & & & \\
\hline Itapura 1 & Canal & 83,09 & 12,46 & 1,15 & 1,58 & 31,63 & 4,74 & 0,38 \\
\hline Itapura 2 & Canal & 93,19 & 13,98 & 1,29 & 2,34 & 46,72 & 7,01 & 0,50 \\
\hline Itapura 3 & Canal & 149,58 & 22,44 & 2,07 & 2,75 & 55,06 & 8,26 & 0,37 \\
\hline Média & Canal & 108,62 & 16,29 & 1,51 & 2,22 & 44,47 & 6,67 & 0,42 \\
\hline Vírgula 1 & Lagoa & 297,15 & 44,57 & 4,12 & 3,40 & 68,08 & 10,21 & 0,23 \\
\hline "Vírgula 2 & Lagoa & 409,22 & "'61,38 & 5,67 & 4,87 & '"97,41 & 14,61 & 0,24 \\
\hline Vírgula 3 & Lagoa & 195,79 & 29,37 & 2,71 & 3,87 & 77,34 & 11,60 & 0,40 \\
\hline 'Vírgula 4 & Lagoa & 277,63 & "'t1,64" & 3,85 & 5,91 & 118,11 & 17,72 & 0,43 \\
\hline Média & Lagoa & 294,95 & 44,24 & 4,09 & 4,51 & 90,24 & 13,54 & 0,32 \\
\hline Ponte de Itapura 1 & Lagoa & & & & 1,95 & 39,09 & 5,86 & \\
\hline Ponte de Itapura 2 & Lagoa & 126,23 & 18,94 & 1,75 & 2,02 & 40,30 & 6,05 & 0,32 \\
\hline Ponte de Itapura 3 & Lagoa & 112,17 & 16,82 & 1,55 & 2,53 & 50,67 & 7,60 & 0,45 \\
\hline Média & Lagoa & 119,20 & 17,88 & 1,65 & 2,17 & 43,36 & 6,50 & 0,39 \\
\hline Pernilongo 1 & Lagoa & 75,54 & 11,33 & 1,05 & 4,37 & 87,39 & 13,11 & 1,16 \\
\hline Pernilongo 2 & Lagoa & 50,51 & 7,58 & 0,70 & 4,04 & 80,75 & 12,11 & 1,60 \\
\hline Pernilongo 3 & Lagoa & 58,23 & 8,73 & 0,81 & 2,72 & 54,41 & 8,16 & 0,93 \\
\hline Média & Lagoa & 61,43 & 9,21 & 0,85 & 3,71 & 74,18 & 11,13 & 1,23 \\
\hline Ferradura 1 & $\overline{\text { Lagoa }}$ & 156,05 & 23,41 & 2,16 & 3,31 & 66,23 & 9,93 & 0,42 \\
\hline Ferradura 2 & Lagoa & 91,02 & 13,65 & 1,26 & 2,17 & 43,43 & 6,51 & 0,48 \\
\hline Média & Lagoa & 123,53 & 18,53 & 1,71 & 2,74 & 54,83 & 8,22 & 0,45 \\
\hline \multicolumn{2}{|c|}{ Média Geral } & 155,39 & 23,31 & 2,15 & 3,19 & 63,77 & 9,57 & 0,56 \\
\hline
\end{tabular}

MF: material vegetal fresco; MS: material vegetal seco em estufa com ventilação a $65^{\circ} \mathrm{C}$ até peso constante. 


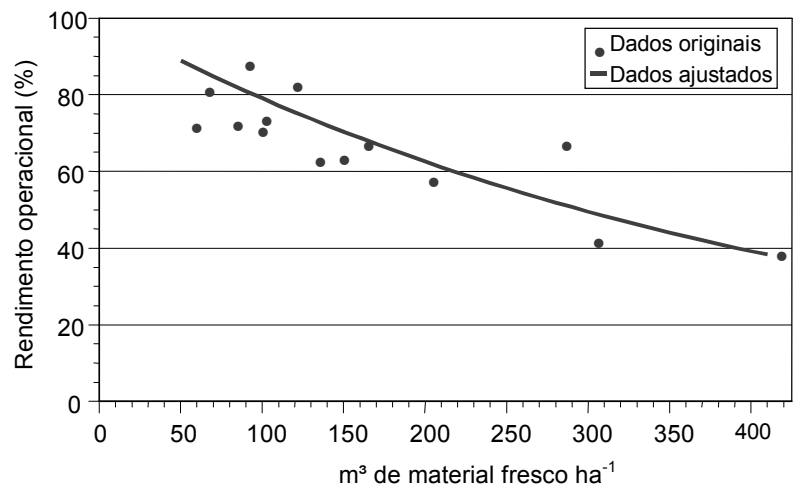

$\left(\mathrm{A}=2 ; \mathrm{B}=-0,001015 ; \mathrm{F}=53,27^{* *} ; \mathrm{R}^{2}=0,7803\right)$.

** significativo a $1 \%$ de probabilidade.

Figura 5 - Representação dos dados originais e do modelo, relacionando o rendimento operacional (\%) à abundância da biomassa de plantas imersas.

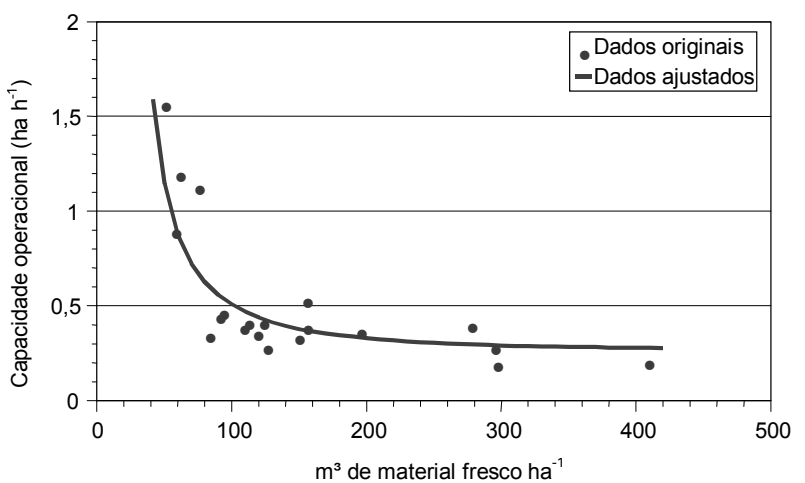

$(\mathrm{A}=3,6607 ; \mathrm{B}=-22,5444 ; \mathrm{C}=0,004315$; assíntota horizontal $\left.(1 / a)=0,2732 ; F=112,17^{* *} ; R^{2}=0,8227\right)$

** significativo a $1 \%$ de probabilidade.

Figura 6 - Representação dos dados originais e do modelo, relacionando a capacidade operacional $\left(\mathrm{ha} \mathrm{h}^{-1}\right)$ à abundância da biomassa de plantas imersas.

Um objetivo adicional deste estudo foi o de estimar a abundância da biomassa de plantas aquáticas imersas no reservatório. Para facilitar a análise dos resultados, foram realizadas análises de regressão entre os valores desta característica e as freqüências acumuladas, segundo o modelo $\mathrm{y}=\mathrm{e}^{\mathrm{a}-\mathrm{e}-\mathrm{b}-\mathrm{cx}}$, em que "y" representa as freqüências acumuladas; "x" representa a abundância de biomassa de plantas aquáticas imersas, expressa em $\mathrm{m}^{3}$ de material fresco ha' ${ }^{-1}$ e "a", "b" e "c" são constantes do modelo utilizado (Figuras 7 e 8). O valor da constante "a" foi estabelecido como sendo 4,60517, considerando que a máxima freqüência acumulada possivel é 100\%.

A conversão dos dados em unidades de peso de material fresco ou de material seco pode ser facilmente feita, considerando que cada $\mathrm{m}^{3}$ de material coletado pesa $150 \mathrm{~kg}$ e que, em termos médios para as três espécies, cada $100 \mathrm{~kg}$ de material fresco coletado produz $9,24 \mathrm{~kg}$ de material seco em estufa a $65^{\circ} \mathrm{C}$.

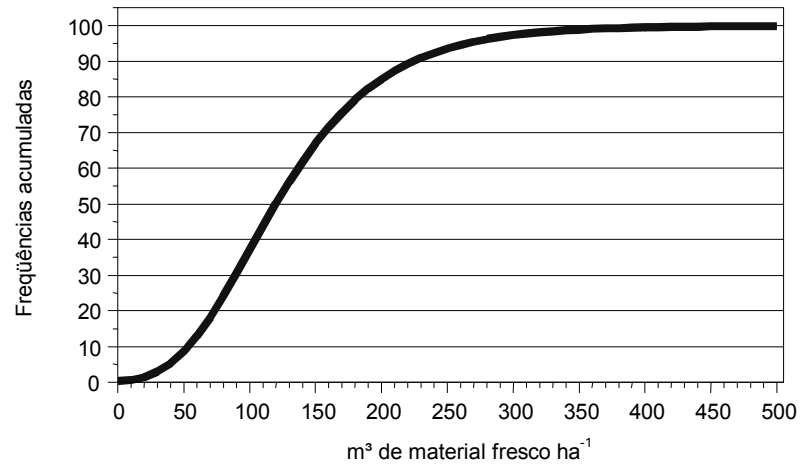

$(\mathrm{a}=4,60517 ; \mathrm{b}=-1,80221 ; \mathrm{c}=0,01813$; assíntota horizontal máxima $\left.\left(\mathrm{e}^{\mathrm{a}}\right)=100 ; \mathrm{F}=2207,74 ; \mathrm{R}^{2}=0,9841\right)$

**significativo a $1 \%$ de probabilidade.

Figura 7 - Representação do modelo, relacionando as estimativas das freqüências acumuladas e as abundâncias de biomassa de plantas imersas.

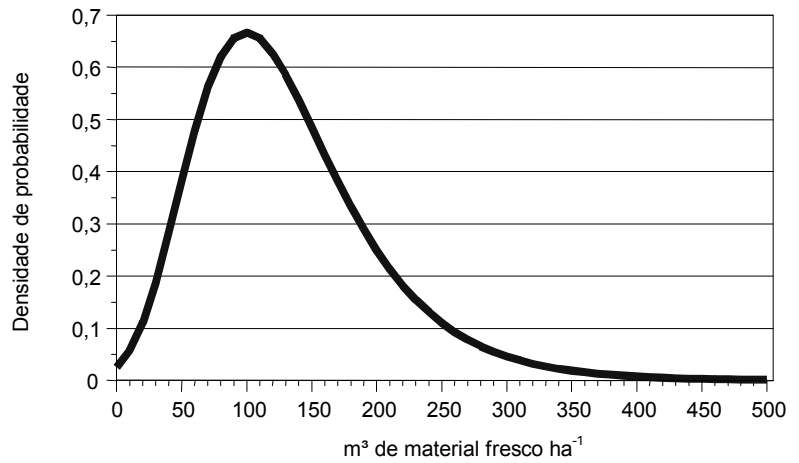

Figura 8 - Representação do modelo, relacionando as densidades de probabilidade e as abundâncias de biomassa de plantas imersas.

A primeira derivada do modelo, apresentada a seguir com a mesma denominação para as variáveis e constantes, permite calcular a densidade de probabilidade em função da abundância de biomassa:

Planta Daninha, Viçosa-MG, v. 23, n. 2, p. 277-285, 2005 


$$
y=c e^{a-b-c x-e^{-b-c x}}
$$

O modelo ajustado indica que $90 \%$ das abundâncias de biomassa, avaliadas segundo a sistemática descrita, situam-se entre 38,89 e 263,26 $\mathrm{m}^{3}$, sendo este o intervalo de confiança a $5 \%$ de probabilidade para a média encontrada $\left(155,39 \mathrm{~m}^{3} \mathrm{ha}^{-1}\right)$. Destaca-se a limitação referente à profundidade de operação da colhedora. Em áreas profundas, as estimativas de biomassa correspondem às quantidades presentes apenas nos 1,6 m superficiais.

A avaliação operacional indicou a impossibilidade de operar a colhedora sem um sistema de navegação fundamentado em DGPS, que permita orientar a movimentação desta nas áreas de controle, preservando a capacidade operacional da colhedora. Esse sistema é importante para garantir que as operações de controle estão sendo realizadas nos locais programados.
Nas coletas realizadas no canal do Tietê (próximo a Itapura) e nas lagoas marginais Virgula e abaixo da ponte de Itapura, foram demarcados polígonos e instruiu-se o operador a trabalhar exclusivamente na área correspondente a estes e minimizar a sobreposição entre as passadas. As operações foram feitas sem orientação pelo sistema de GPS, ou seja, ele foi utilizado somente para registro das coordenadas.

A análise das Figuras 9 a 11 indica a grande dificuldade de orientação em condições normais de operação. Adicionalmente, essa falta de orientação inviabiliza a manutenção de espaçamentos uniformes entre as faixas de coleta, além de levar à sobreposição das passadas, que deve ser vista como uma importante limitação à capacidade operacional efetiva da colhedora, uma vez que poderá operar duas ou até mais vezes no mesmo local.
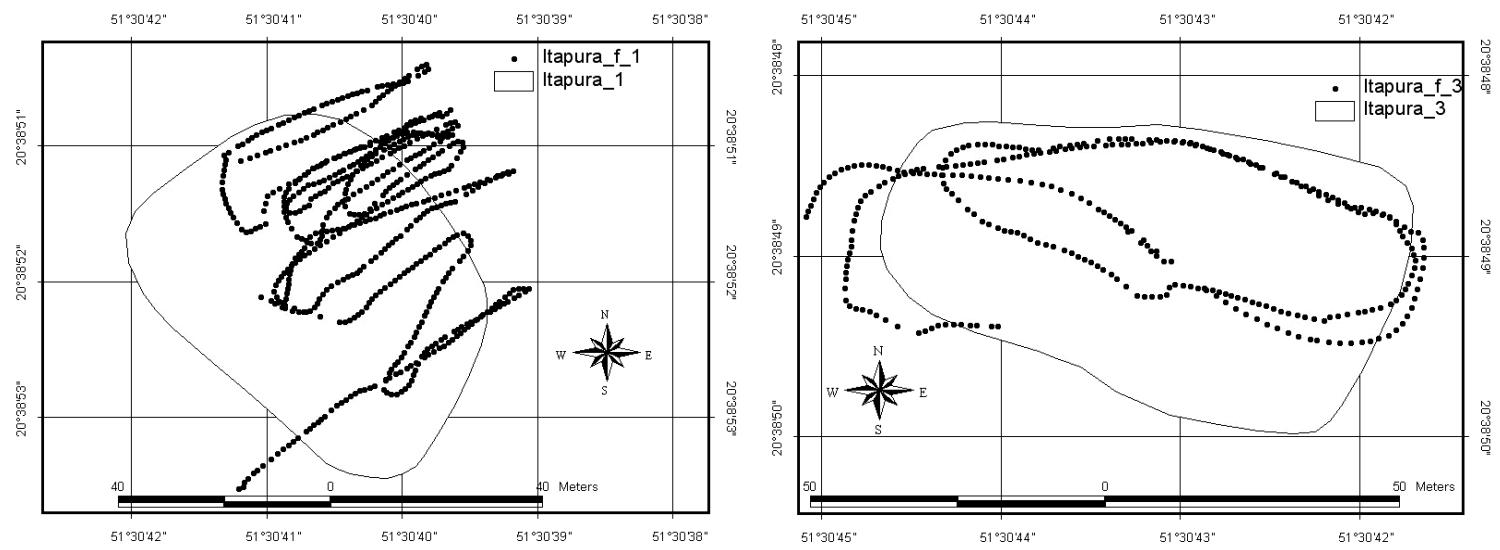

Figura 9 - Esquemas representando a movimentação da colhedora nas coletas realizadas no canal do rio Tietê, próximo à cidade de Itapura.
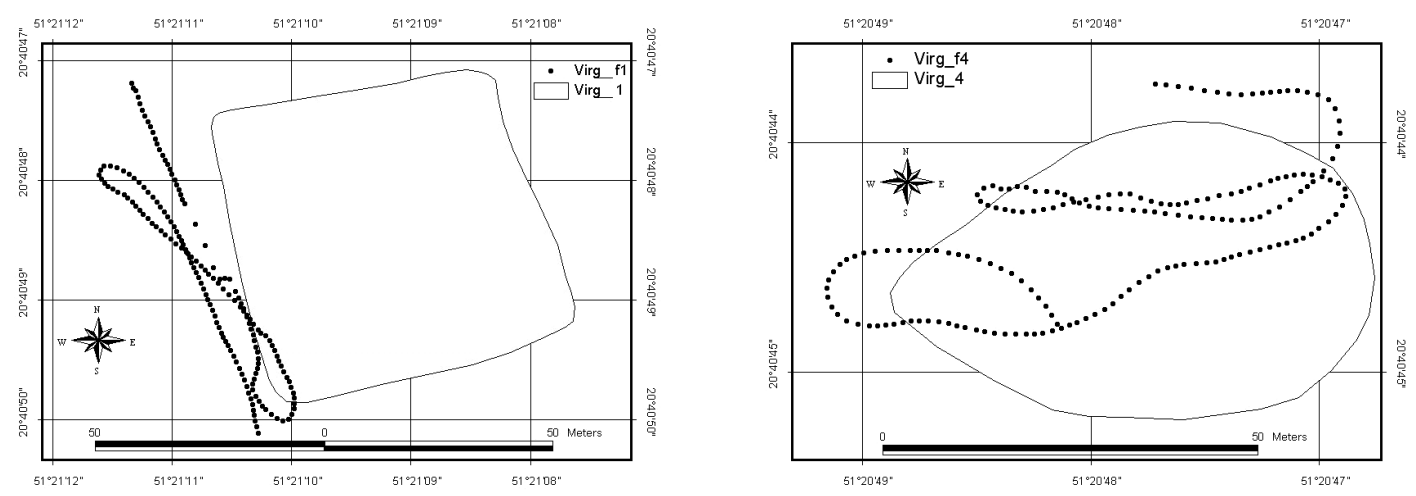

Figura 10 - Esquemas representando a movimentação da colhedora em coletas realizadas na Lagoa Vírgula. 

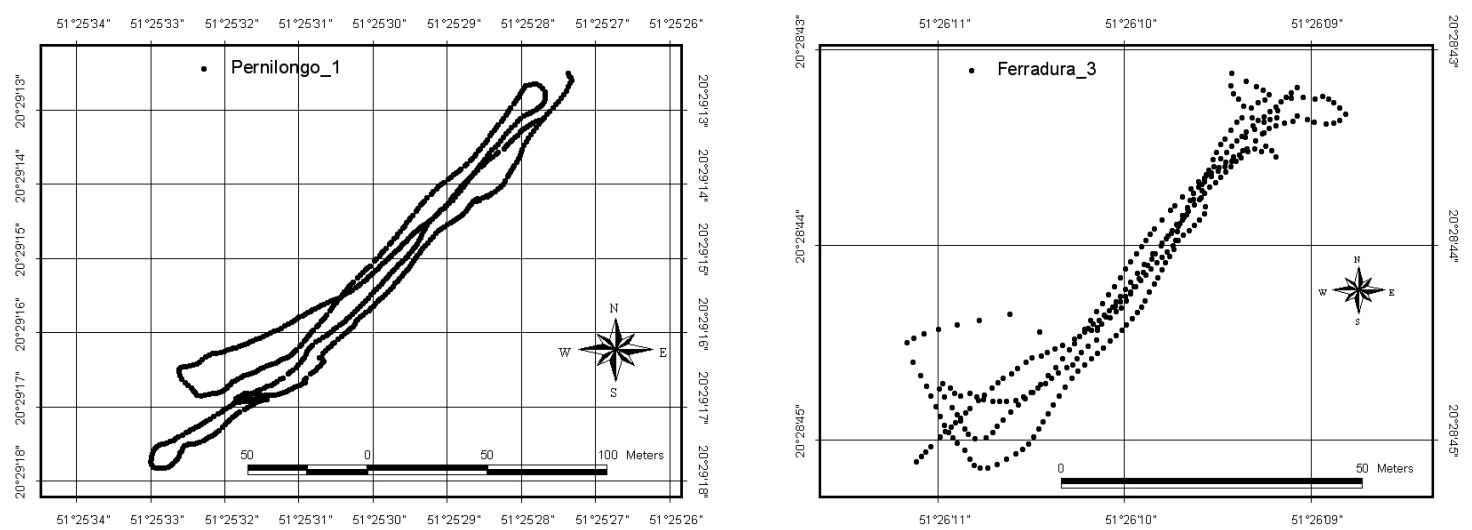

Figura 11 - Esquemas representando a movimentação da colhedora em coletas realizadas nas lagoas Pernilongo e Ferradura.

A avaliação operacional indicou, ainda, a necessidade de que os pontos de descarte das plantas imersas estejam próximos dos locais de coleta, a fim de que o rendimento e a capacidade operacional não sejam bastante reduzidos. Minimizar o deslocamento para descarregamento da colhedora é sobremaneira importante quando o controle mecânico é feito em áreas intensamente infestadas por plantas imersas.

\section{AGRADECIMENTOS}

À Companhia Energética de São Paulo CESP, pelo apoio técnico durante a execução deste estudo.

\section{LITERATURA CITADA}

BRAGA, M. F. S. Estudo de recifes artificiais como atratores de peixes no reservatório de Volta Grande, Rio Grande (MG-SP). Acta Limn. Bras., v. 14, n. 2, p. 65-76, 2002.

CORRÊA, M. R. Composição química, bromatológica e decomposição de Egeria densa, Egeria najas e Ceratophyllum demersum coletadas no reservatório de Jupiá. 2002. 101 f. Dissertação (Mestrado em Agronomia / Agricultura)-Universidade Estadual Paulista, Botucatu, 2002.
CORRÊA, M. R.; VELINI, E. D.; ARRUDA, D. P. Teores de metais na biomassa de Egeria densa, Egeria najas e Ceratophyllum demersum. Planta Daninha, v. 20, p. 45-49, 2002. (Edição especial)

CORRÊA, M. R.; VELINI, E. D.; ARRUDA, D. P. Composição química e bromatológica de Egeria densa, Egeria najas e Ceratophyllum demersum. Planta Daninha, v. 21, p. 7-13, 2003. (Edição especial)

MARCONDES, D. A. S. et al. Eficiência do fluridone no controle de plantas aquáticas submersas sobre algumas características ambientais. Planta Daninha, v. 20, p. 63-71, 2002. (Edição especial)

MARCONDES, D. A. S. et al. Eficiência de fluridone no controle de plantas aquáticas submersas no reservatório de Jupiá. Planta Daninha, v. 21, p. 69-77, 2003. (Edição especial)

POMPÊO, M. L. M.; MOSCHINI-CARLOS, V. Macrófitas aquáticas e perifiton: aspectos ecológicos e metodológicos. São Carlos: RiMa, 2003. 134 p.

VELINI, E. D. Controle de plantas aquáticas. In: CONGRESSO BRASILEIRO DA CIÊNCIA DAS PLANTAS DANINHAS, 22., Foz do Iguaçu, 2000. Palestras... Foz do Iguaçu: SBCPD, 2000. p. 137-147. 